\title{
A combined SEM, CV and EIS study of multi-layered porous ceramic reactors for flue gas purification
}

He, Zeming; Andersen, Kjeld Bøhm; Nygaard, Frederik Berg; Kammer Hansen, Kent

Published in:

Ceramics International

Link to article, DOI:

10.1016/j.ceramint.2012.05.097

Publication date:

2013

Link back to DTU Orbit

Citation (APA):

He, Z., Andersen, K. B., Nygaard, F. B., \& Kammer Hansen, K. (2013). A combined SEM, CV and EIS study of multi-layered porous ceramic reactors for flue gas purification. Ceramics International, 39(1), 847-851. https://doi.org/10.1016/j.ceramint.2012.05.097

\section{General rights}

Copyright and moral rights for the publications made accessible in the public portal are retained by the authors and/or other copyright owners and it is a condition of accessing publications that users recognise and abide by the legal requirements associated with these rights.

- Users may download and print one copy of any publication from the public portal for the purpose of private study or research.

- You may not further distribute the material or use it for any profit-making activity or commercial gain

- You may freely distribute the URL identifying the publication in the public portal 


\title{
A combined SEM, CV and EIS study of Multi-layered Porous Ceramic Reactors for Flue Gas Purification
}

\author{
Zeming He, Kjeld Bøhm Andersen, Frederik Berg Nygaard, Kent Kammer Hansen \\ Department of Energy Conversion and Storage \\ Technical University of Denmark \\ DK-4000 Roskilde, DENMARK
}

\begin{abstract}
The effect of sintering temperature of 12-layered porous ceramic reactors (comprising 5 cells) was studied using scanning electron microscopy (SEM), cyclic voltammetry $(\mathrm{CV})$ and electrochemical impedance spectroscopy (EIS). The difference in microstructures of the reactors was evaluated by SEM. Additional information on the influence of sintering temperature on the properties of the reactors could be gained by the use of EIS. The present work has provided the first set of fundamental electrochemical data and their interpretation in terms of fabrication conditions, for the multi-layered porous ceramic reactors.
\end{abstract}

Key words: Multi-layered electrochemical reactors; Porous ceramic; Scanning electron microscopy (SEM); Voltammetry; Electrochemical impedance spectroscopy (EIS) 


\section{Introduction}

The diesel-powered engines display the advantages of high thermal efficiency, durability and reliability compared to the gasoline-powered engines [1]. However, one of the main problems is the emission of $\mathrm{NO}_{\mathrm{x}}(\mathrm{x}=1,2)$ and soot particulates during operation, which still exists and limits the practical application of the diesel engines [1,2]. Therefore, there has been a great demand on effective and economical methods for the purification of the exhaust gases. According to the literature several approaches have been reported for the efficient removal of both $\mathrm{NO}_{\mathrm{x}}$ and soot particles emitted from the diesel engines [1, 3, 4]. Among them the use of the electrochemical cell for a simultaneous removal of $\mathrm{NO}_{\mathrm{x}}$ and soot particle has been proven to be a novel and effective solution [5, 6]. It is worth mentioning that the reduction of $\mathrm{NO}_{\mathrm{x}}$ and the oxidation of soot particles take place at the cathode and the anode of the cell, respectively, which facilitates the simultaneous purification.

Recently, some attempts to improve the properties of electrochemical cells have been carried out via materials selection and optimization [7]. In our previous work [8], flat, crack-free and layered electrochemical reactors (a series of cells) with a novel configuration comprising mechanically supporting layer, electrode and electrolyte were successfully produced via the processes of slurry preparation, tape casting, lamination and sintering, and the effect of sintering temperature on the materials properties (shrinkage, porosity, pore size, flow rate and room-temperature electrical conductivity) was investigated.

The present work is focused on the microstructure and the electrochemistry of the reactors sintered at different temperatures. The microstructures of the sintered samples were investigated by using the scanning electron microscopy (SEM). While, for the investigated sample's characterization of the electrochemical behavior, both current density-voltage curves and impedance spectra at different temperatures and different oxygen partial pressures were measured and evaluated. In this study, no $\mathrm{NO}_{\mathrm{x}}$ or soot is introduced in the measurement, to make the electrochemical characterization of the produced reactors as simple as possible. However, it is noted that these electrochemical processes are could also be applied when $\mathrm{NO}_{\mathrm{x}}$ and soot are present. The present work is an attempt to provide the first set of fundamental electrochemical data and their 
interpretation for the efficient production of multi-layered porous ceramic reactors sintered at different temperatures.

\section{Experimental Procedure}

The designed electrochemical reactor were comprised of 12 ceramic layers: 1 mechanically supporting layer of lanthanum strontium manganate (LSM)-yttria stabilized zirconia (YSZ), 6 electrode layers of LSM-gadolinium-doped cerium oxide (CGO) and 5 electrolyte layers of CGO. The samples were fabricated via the processes of slurry preparation, tape casting, lamination and sintering. The details of the layer composition and the fabrication procedure of the reactors were reported in our previous work [8]. The present work confines the investigation to the samples sintered at 1150,1200, 1250 and $1300{ }^{\circ} \mathrm{C}$.

A TM 1000 scanning electron microscope (Hitachi, Japan) was used in order to examine the cross section of the polished reactor to reveal its microstructure. For the characterization of the electrochemical performance, the sintered samples were cut into $8 \times 8 \mathrm{~mm}^{2}$ squares. To ensure good in-plane conductivity, Pt paste was applied on the both ends of the cut reactor. Afterwards the Pt-coated samples were heat-treated at $1000{ }^{\circ} \mathrm{C}$ for 6 hours in a furnace (Heraeus, Germany) with both the heating rate and the cooling rate to be $5{ }^{\circ} \mathrm{C} / \mathrm{min}$. After having the contacting electrode on the surfaces, the reactors were sandwiched between two platinum meshes supported by alumina pellets in a testing rig (Scandia, Denmark), where both the ranges in temperature and oxygen partial pressure $\left(P_{\mathrm{O} 2}\right)$ for all the tests could be adjusted and controlled. The details in this set-up were described elsewhere [9]. For the samples investigated in air, the measurement temperatures were $325,350,375,400$ and $425{ }^{\circ} \mathrm{C}$, respectively. For the samples investigated at $400{ }^{\circ} \mathrm{C}$, the measurement oxygen partial pressures were $0.01,0.02,0.05$, $0.1,0.2,0.5$ and $1 \mathrm{~atm}$, respectively. A total gas flow rate of $100 \mathrm{~mL} / \mathrm{min}$ was used for all the testing. At a given temperature or $P_{\mathrm{O} 2}$, the current density-voltage relations and the impedance spectra of the reactors were measured using a SI 1250 frequency response analyzer and a SI 1287 electrochemical interface (Solartron, England). The current density-voltage curves were recorded with a sweep rate of $10 \mathrm{mV} / \mathrm{s}$. The measurements were initiated at open circuit voltage (OCV) and run in the cathodic current direction 
first. Then the voltammogram was recorded between $-3 \mathrm{~V}$ to $3 \mathrm{~V}$ versus OCV. The impedance data were analyzed using the PC-DOS program 'EQIVCT' developed by Boukamp [10]. Finally, the impedance data were fitted with three suppressed semicircles.

\section{Results and Discussion}

Figure 1 shows the SEM micrographs of the sample sintered at $1200{ }^{\circ} \mathrm{C}$, from which the configuration of the reactor is revealed. With respect to Figure 1a, the electrochemical reactor comprises 1 thicker supporting layer of LSM-YSZ, 6 electrode layer of LSMCGO and 5 electrolyte layer of CGO. The layers of the electrode and the electrolyte are alternately arranged. The estimated thicknesses of LSM-YSZ, LSM-CGO and CGO are to be 170,30 and $20 \mu \mathrm{m}$, respectively. To facilitate the treatment of the flue gases, the sintered electrochemical reactor is porous, which could be seen more clearly from the high-magnification SEM images of the support, the electrode and the electrolyte, as illustrated in Figures $1 \mathrm{~b}$ and 1c. It is worth noting that the pore inter-connectivity of the supporting layer is not as good as that of the electrode and/or the electrolyte. This is mainly attributed to the fact that different contents and particle sizes of the different poreformers were added in order to generate porosity for the supporting layer, the electrode and the electrolyte, as described in our previous work [8].

The thicker layer of LSM-YSZ mainly provides enhanced mechanical support, as well as for the electrical conductivity of the reactor. When the external power is applied on the reactor, $\mathrm{NO}_{\mathrm{x}}$ is reduced at the first cathode layer of LSM-CGO to form nitrogen and oxygen anions. The oxygen anions transport through the electrolyte layer of CGO to the anode layer of LSM-CGO, where the soot particles react with these active oxygen anions and are removed by oxidation. The electrons released from the oxidation of the soot particles are further used to reduce the $\mathrm{NO}_{\mathrm{x}}$ molecules while the produced oxygen anions further travel through the next electrolyte layer to the next anode where the oxidation of soot occurs. As a result, the reactions of the reduction of $\mathrm{NO}_{\mathrm{x}}$ and the oxidation of soot particles take place layer by layer and therefore the simultaneous removal of them is achieved. In summary, this multi-layered porous ceramic reactor could be considered as an oxygen pump to supply oxygen species through the electrolyte. The intermediate 
electrode layers of LSM-CGO is working as both cathode and anode to facilitate the reduction and oxidation processes at the same time.

The current density-voltage curves obtained at a fixed sintering temperature and a given measurement temperature are presented in Figure 2. With respect to Figure 2a, the voltammograms of the reactor sintered at $1300{ }^{\circ} \mathrm{C}$ and measured at different temperatures in air, reveal that the current density increases with increasing the voltage for all the applied temperatures. The absolute value of the current density at a given voltage increases with increasing the measurement temperature, which indicates that higher temperature enhances the electrochemical performance of the reactor. Moreover, it is worth mentioning that the effect of measuring temperature has also been recorded for the I-V curves of the remaining reactors even though they were sintered at other temperatures (not shown in this article). In Figure 2b, the voltammograms of the samples sintered at different temperatures and measured at a constant temperature of $425{ }^{\circ} \mathrm{C}$ in air are shown and the absolute value of the current density at a given voltage seems to increase with increasing the sintering temperature. This is attributed to the density/porosity effect. In general, higher sintering temperature leads to higher density/lower porosity, which enhances the transport of oxide anions in the reactors. The effect of sintering temperature is also pronounced in the current density-voltage curves of the reactors measured at other temperatures (not shown). The sintering temperature effect will be addressed in more details at the subsequent presentation on the electrochemical impedance spectroscopy (EIS).

The impedance spectra of the samples sintered at 1150 and $1300{ }^{\circ} \mathrm{C}$ and measured at different oxygen partial pressures at $400{ }^{\circ} \mathrm{C}$ are presented in Figure 3. For the investigated reactors, remarkable changes of the impedance with the $P_{\mathrm{O} 2}$ are displayed in low frequency arcs. While higher $P_{\mathrm{O} 2}$ resulted in lower polarization resistances.

The EIS data were fitted using an equivalent circuit with a resistance $R$ in series with three $R Q$ sub-circuits, where $Q$ is a constant phase element. As an illustration, Figure 4 shows the fitting result of the impedance spectrum of the reactor sintered at $1150{ }^{\circ} \mathrm{C}$ and measured at $0.01 \mathrm{~atm}$ at $400{ }^{\circ} \mathrm{C}$. A good agreement between the fitting curve and the experimental data is observed, which validates the used model. With respect to Figure 4, the impedance data consist of three arcs in terms of high, middle and low frequencies. 
The $P_{\mathrm{O} 2}$ dependence of the individual arcs could be well described using a power law. The values of the power $n$ determined from the fitting of the power-law plots (not shown) are given in Table 1. On the basis of the determined $n$ values, a tentative interpretation of the EIS data was obtained when varying the $P_{\mathrm{O} 2}$ at $400{ }^{\circ} \mathrm{C}$ in combination with the use of a mechanism suggested for solid oxide fuel cell (SOFC) cathodes [11]. The low frequency arc is normally attributed to a slow redox reaction at the surface of the electrode. Though different impedance values (higher in the $1150{ }^{\circ} \mathrm{C}$-sintered reactor) were recorded, the $P_{\mathrm{O} 2}$ dependence of the low frequency arc is almost the same for the two reactors with different sintering temperatures, where the $n$ values are around 1/4. According to Takeda et al. [12], such a $P_{\mathrm{O} 2}$ dependence could be due to the reduction of oxygen species at the surface of the electrode and incorporation of oxygen anions in the electrode. The $P_{\mathrm{O} 2}$ dependence of the middle frequency arc is the one that changes the most with the sintering temperature of the reactors. For the reactor sintered at $1300{ }^{\circ} \mathrm{C}$, the $P_{\mathrm{O} 2}$ dependence $n$ is around 1/10. A low $P_{\mathrm{O} 2}$ dependence of this kind of arc was also observed at higher temperature for LSM-YSZ electrodes [13]. The reactor sintered at $1150{ }^{\circ} \mathrm{C}$ has a much higher $P_{\mathrm{O} 2}$ dependence, where the $n$ is around $1 / 5$. Such a $P_{\mathrm{O} 2}$ dependence was also observed at higher temperatures for LSM-YSZ electrodes, and it was suggested to be due to the transport of oxide anions in the electrode [13]. This strongly suggests that the middle frequency arcs are due to different processes for the reactors sintered at different temperatures. The reactor sintered at higher temperature contains larger particles and the particles seem to be better connected compared to the reactor sintered at lower temperature, as illustrated in Figure 5. Thus the microstructures of both electrode and electrolyte of the two reactors, is probably the factor that makes the transport of ions in the electrode much smoother. The magnitude of the middle frequency arc is indeed much higher for the reactor sintered at lower temperature than at the higher temperature. The high frequency arc is virtually independent of $P_{\mathrm{O} 2}$. This arc is most likely due to transport of oxygen anions in the electrolyte layers. The magnitude of this arc is much higher when the reactor was sintered at $1150{ }^{\circ} \mathrm{C}$ than at $1300{ }^{\circ} \mathrm{C}$. This shows that the sintering of the electrolyte layers is insufficient at $1150{ }^{\circ} \mathrm{C}$, compared to that at $1300{ }^{\circ} \mathrm{C}$. 
The fitting results of the EIS data for the reactors, sintered at the four different temperatures and measured at $400{ }^{\circ} \mathrm{C}$ in air, are shown in Figure 6. The magnitudes of the high and the middle frequency arcs are seen to decrease with increasing the sintering temperature of the reactors. This is consistent with the fact that a higher sintering temperature results in a better inter-connectivity of the particles in the reactors, enhancing the transport properties of the reactors, as explained earlier. However, the magnitude of the low frequency arc decreases with increasing the sintering temperature until $1250{ }^{\circ} \mathrm{C}$, while it increases with a further increase of the sintering temperature to $1300{ }^{\circ} \mathrm{C}$. This shows that the activity, for the reduction of oxygen species at the surface of the electrode and incorporation of oxide anions in the electrode, is highest for the reactor sintered at $1250{ }^{\circ} \mathrm{C}$. Two effects may play roles in this phenomenon; the sintering of the reactors and the surface area of the electrodes. It is known that when the sintering temperature of the reactor increases, the inter-connectivity of the particles increases. This leads to a better contact between the particles, which in turn lowers the resistance. However, an increase in sintering temperature also leads to coarsening of particles and lowering the surface area of the electrodes. The latter effect may explain the increase in the magnitude of the low frequency arc, when the sintering temperature increases from $1250{ }^{\circ} \mathrm{C}$ to $1300{ }^{\circ} \mathrm{C}$. According to the investigated EIS data, it is noted that the variation of the oxygen partial pressure makes it possible to understand the electrochemical properties of the porous reactors. As stated in the introduction part, the electrochemical processes are almost the same whether $\mathrm{NO}_{\mathrm{x}}$ and/or soot is present or not: the high and middle frequency arcs are independent of the atmosphere, as they are related to transport of oxygen anions in the ceramics, while the low frequency arc is of remarkable $P_{\mathrm{O} 2}$ dependance, as it has the correlation with the reaction activity of oxygen species with the electrode. The oxygen pumping property is important for $\mathrm{NO}_{\mathrm{x}}$ reduction and soot oxidation.

\section{Conclusions}

It was shown that the microstructure of the 12-layered porous ceramic reactors is strongly dependent on the sintering temperature. A higher sintering temperature leads to a better inter-connectivity between the particles in the reactors. Additionally, the EIS reveals that different processes dominate the impedance spectra when the reactors are sintered at low 
or high temperature. This is thought to be due to the better inter-connectivity of the particles for the rectors sintered at high temperature. The reactor sintered at $1300{ }^{\circ} \mathrm{C}$ shows the highest activity.

\section{Acknowledgement}

Dr. Nikolaos Bonanos is thanked for fruitful discussions. This work is supported by the Strategic Research Council of Denmark with project number of 2104-05-067. 


\section{References}

[1] H. Christensen, Z.S. Rak, A novel diesel particulate converter, Catal. Today, 75 (2002) 451-457

[2] S. Bredikhin, K. Matsuda, K. Maeda, M. Awano, Novel low voltage electrochemical cell for NO decomposition, Solid State Ionics, 149 (2002) 327-333

[3] S. Bredikhin, K. Maeda, M. Awano, NO decomposition by an electrochemical cell with a mixed oxide working electrode, Solid State Ionics 144 (2001) 1- 9

[4] S. Bredikhin, K. Maeda, M. Awano, Low current density electrochemical cell for NO decomposition, Solid State Ionics 152-153 (2002) 727-733

[5] K. Kammer, Electrochemical DeNOx in solid electrolyte cells - an overview, Appl. Catal. B, 58 (2005) 33-39

[6] K. Hamamoto, Y. Fujishiro, M. Awano, Simultaneously removal of nitrogen oxides and diesel soot particulate in nano-structured electrochemical reactor, Solid State Ionics, 177 (2006) 2297-2300

[7] S. Bredikhin, K. Hamamoto, Y. Fujishiro, M. Awano, Electrochemical reactors for NO decomposition. Basic aspects and a future, Ionics, 15 (2009) 285-299

[8] Z. He, K.B. Andersen, F.B. Nygaard, N. Bonanos, M. Menon, K.K. Hansen, Sintering Effect on Material Properties of Electrochemical Reactors Used for Removal of Nitrogen Oxides and Soot Particles Emitted from Diesel Engines, Fuel Cells, 10 (2010) 636-642

[9] M. Jørgensen, M. Mogensen, Impedance of solid oxide fuel cell LSM/YSZ composite cathodes, J. Electrochem. Soc., 148 (2001) A433-A442

[10] B.A. Boukamp, A Package for Impedance Admittance Data-Analysis, Solid State Ionics, 20 (1985) 31-44

[11] E. Siebert, A. Hammouche, M. Kleitz, Impedance spectroscopy analysis of La 1${ }_{\mathrm{x}} \mathrm{Sr}_{\mathrm{x}} \mathrm{MnO}_{3}$-yttria-stabilised-zirconia electrode-kinetics, Electrochim. Acta, 40 (1995) 1741-1753

[12] Y. Takeda, R. Kanno, M. Noda, Y. Tomida, O. Yamamoto, Cathodic polarization phenomena of perovskite oxide electrodes with stabilized zirconia, J. Electrochem. Soc., 134 (1987) 2656-2661 
[13] K.K. Hansen, M. Menon, J. Knudsen, N. Bonanos, M. Mogensen, The Effect of a CGO Barrier Layer on the Performance of LSM/YSZ SOFC Cathodes, J.

Electrochem. Soc., 157 (2010) B309-B313 
Table 1 Values of power $n$ determined from the fitting of resistance versus oxygen partial pressure (1: high frequency arc, 2: middle frequency arc and 3: low frequency arc)

\begin{tabular}{|c|c|c|c|}
\hline $\begin{array}{c}\text { Sintering } \\
\text { temperature }\left({ }^{\circ} \mathrm{C}\right)\end{array}$ & 1 & 2 & 3 \\
\hline 1150 & $\sim 0$ & 0.21 & 0.24 \\
\hline 1300 & $\sim 0$ & 0.09 & 0.25 \\
\hline
\end{tabular}




\section{Figure captions}

Figure 1 SEM images of the electrochemical reactor sintered at $1200{ }^{\circ} \mathrm{C}$ : (a) entire reactor, (b) supporting layer, (c) electrode and electrolyte.

Figure 2 Current density-voltage curves of the electrochemical reactors: (a) sintered at $1300{ }^{\circ} \mathrm{C}$ and measured at different temperatures in air and (b) sintered at different temperatures and measured at $425{ }^{\circ} \mathrm{C}$ in air.

Figure 3 Impedance spectra of the electrochemical reactors measured at different oxygen partial pressures at $400{ }^{\circ} \mathrm{C}$ : (a) sintered at $1150{ }^{\circ} \mathrm{C}$ and (b) sintered at $1300{ }^{\circ} \mathrm{C}$.

Figure 4 Measured (circles) and fitting (solid line) impedance spectra for the reactor sintered at $1150{ }^{\circ} \mathrm{C}$, though measured at an oxygen partial pressure of 0.01 atm and 400 ${ }^{\circ} \mathrm{C}$.

Figure 5 SEM images of the electrochemical reactors sintered at: (a) $1150{ }^{\circ} \mathrm{C}$ and (b) $1300{ }^{\circ} \mathrm{C}$.

Figure 6 Contributions from the individual arcs as a function of the sintering temperature of the reactors measured at $400{ }^{\circ} \mathrm{C}$ in air. The data were fitted with three $R Q$ 's in series. $R_{1}$ high frequency arc, $R_{2}$ middle frequency arc and $R_{3}$ low frequency arc. 


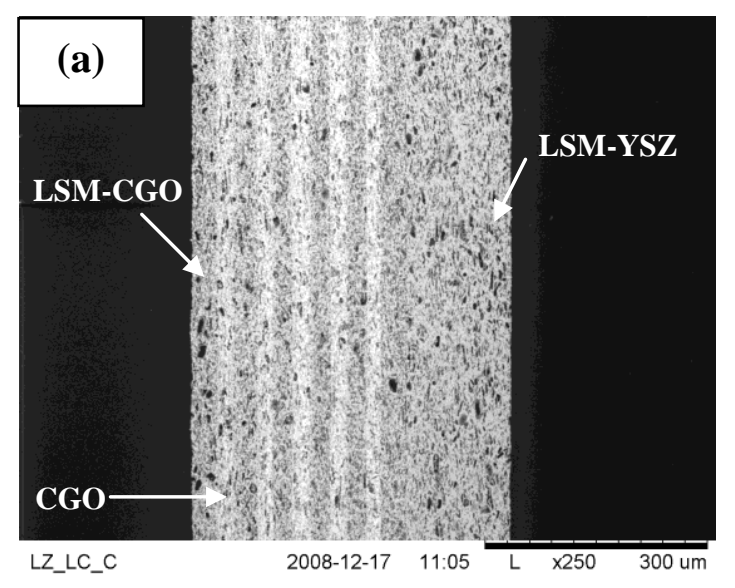

1200C_250LZ_LC_C

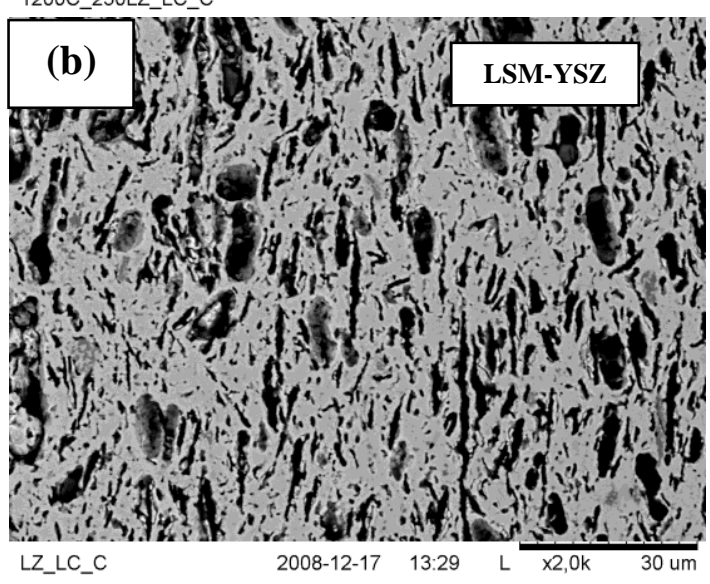
1200C_2000LZ

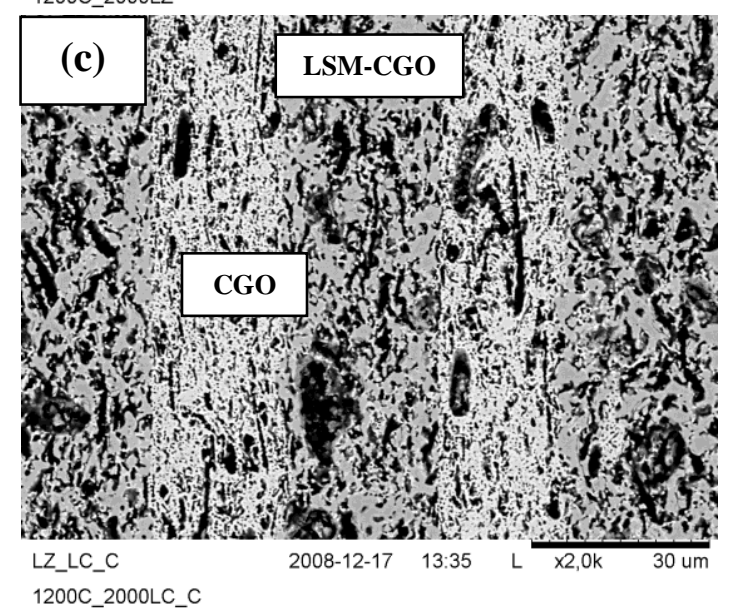

Figure 1 

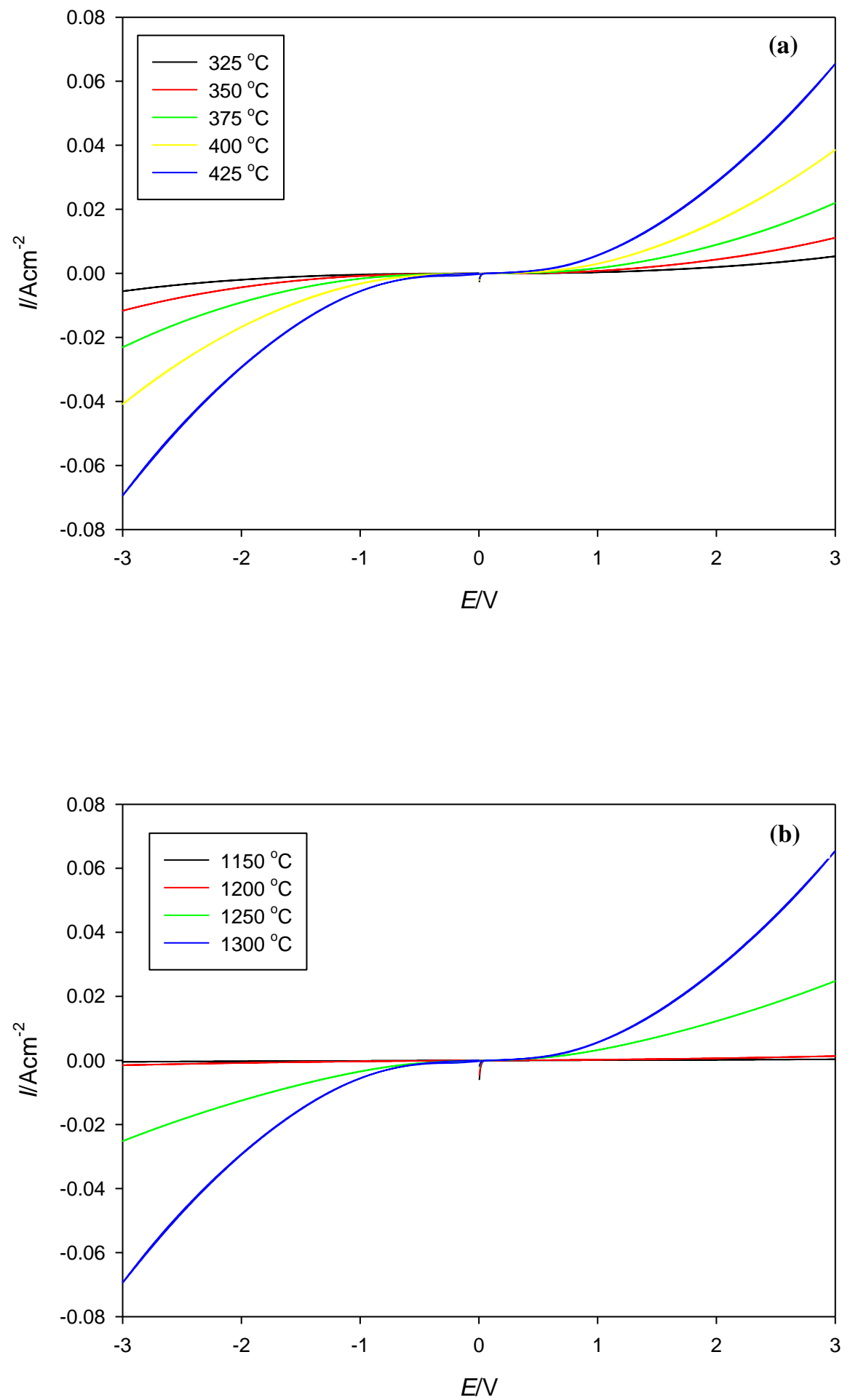

Figure 2 

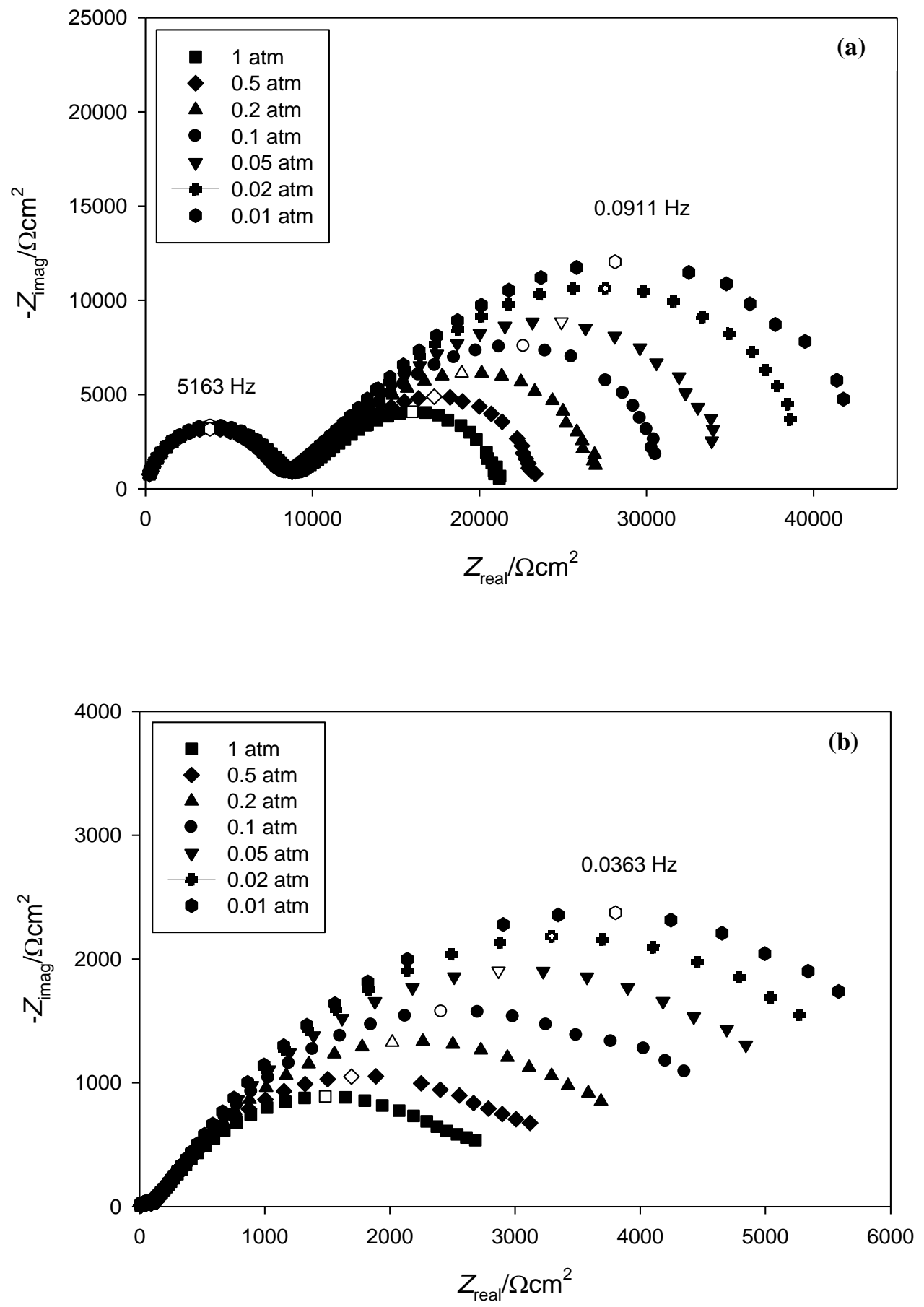

Figure 3 


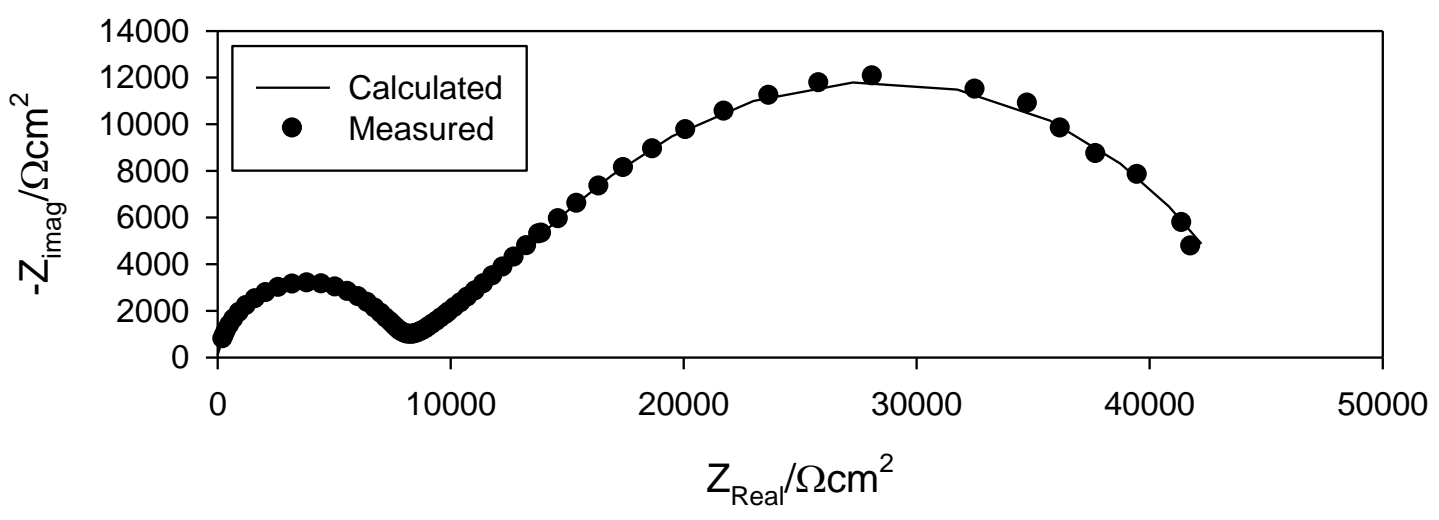

Figure 4 


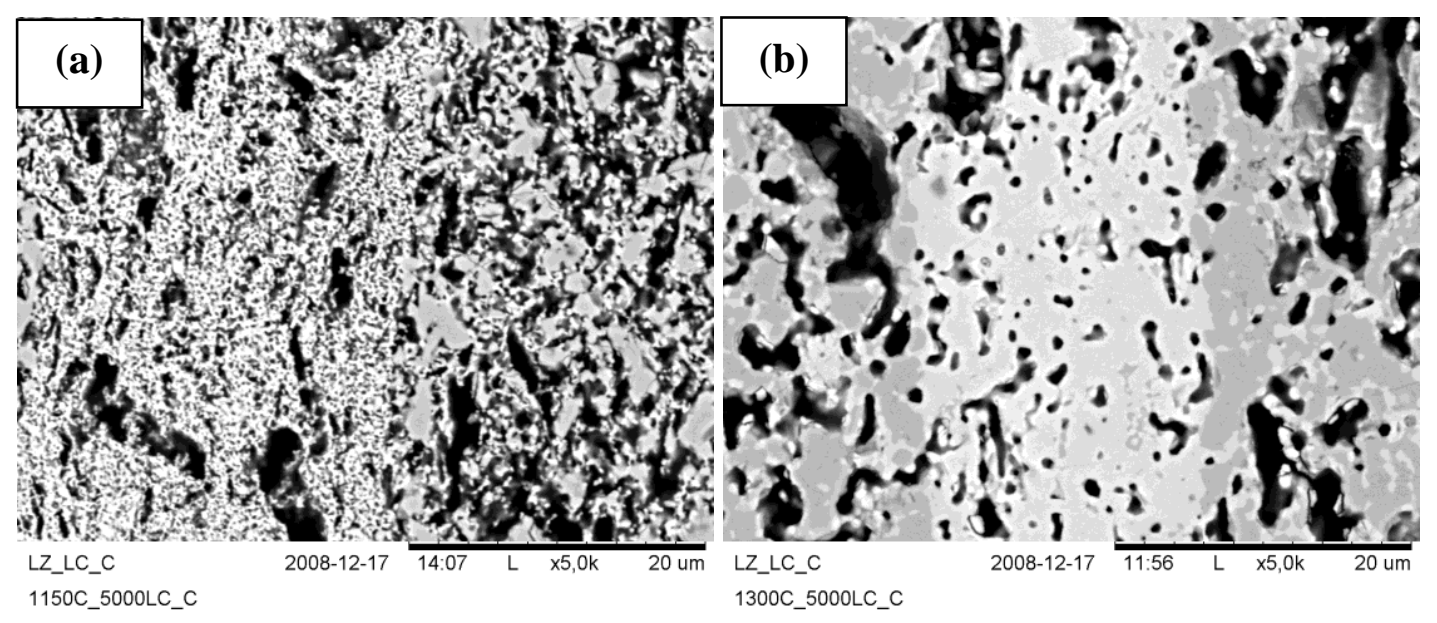

Figure 5 


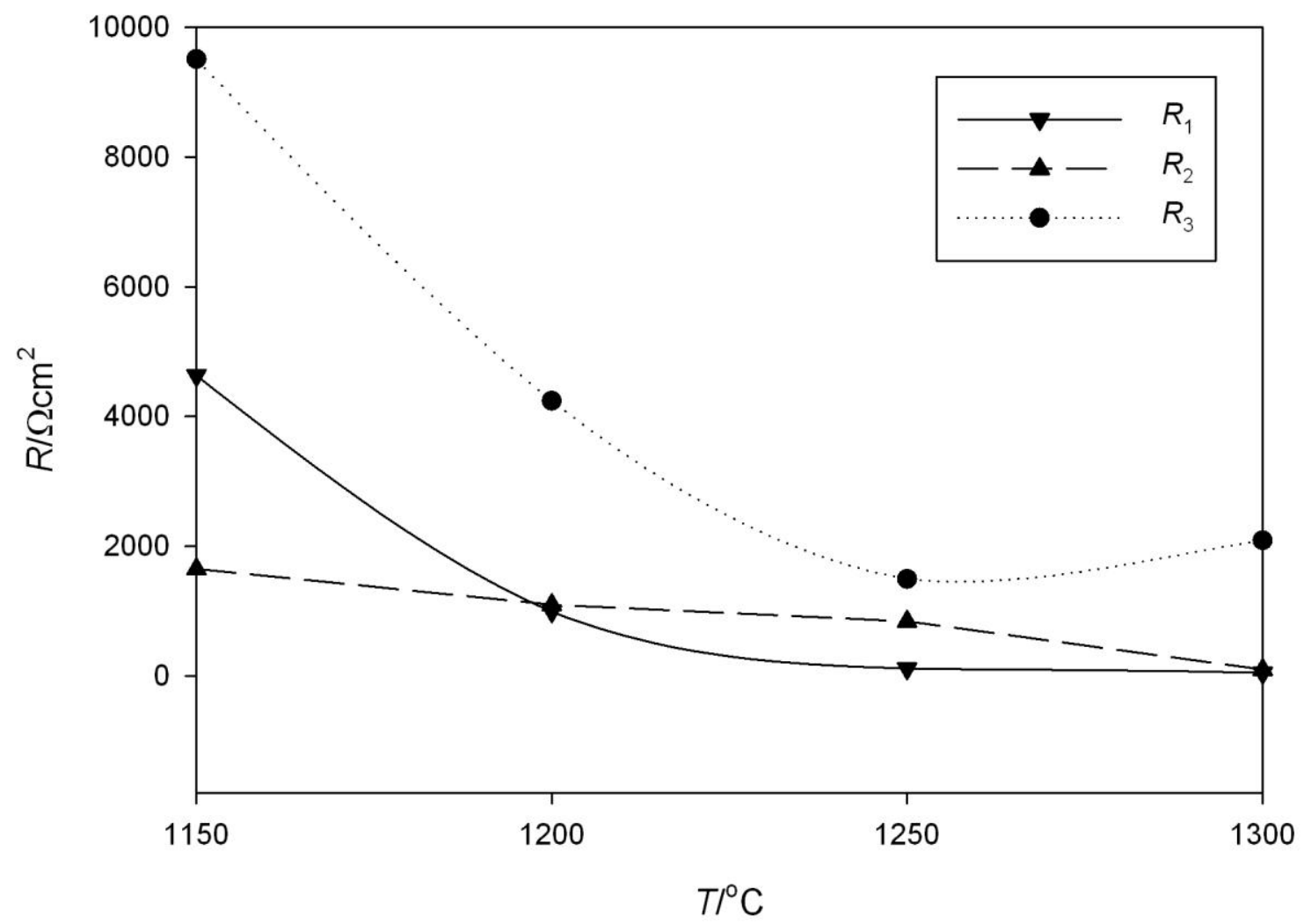

Figure 6 